\title{
História da educação no Brasil: da Constituição Federativa de 1988 a Base Nacional Comum Curricular (BNCC)
}

\author{
History of education in Brazil: from the Constitution of the Federative Republic of 1988 to the \\ Common National Curriculum Base (BNCC) \\ Historia de la educación em Brasil: de la Constitución de la República Federativa de 1988 a la Base \\ Curricular Nacional Común (BNCC)
}

\section{Resumo}

As sucessivas mudanças nas políticas educacionais brasileira, têm ocasionado consequências agravantes na educação. Diante disso, o presente artigo tem como finalidade evidenciar como se deu o processo de elaboração da Base Nacional Comum Curricular através dos documentos educacionais publicados desde a Constituição de 1988. Trata-se de uma pesquisa bibliográfica e documental, de natureza avançada, de caráter exploratório e explicativo, e com uma abordagem qualitativa, onde foram estudados diversos documentos desde a Constituição de 1988 até a última versão da BNCC, e artigos científicos. Para uma melhor compreensão acerca da pesquisa foi construída uma ordem cronológica entre os principais documentos educacionais. Diante de todo trabalho conclui-se que o processo de implementação da BNCC é algo que foi sendo planejado durante os anos por apenas uma parte da sociedade, que deseja que nossa população passe a seguir todo o pensamento capitalista, realizando inicialmente mudanças nas políticas educacionais, visto que quando fazemos alterações nos métodos educacionais estamos realizando mudanças no modo de pensar da sociedade.

Palavras-chave: Educação; História; Base Nacional Comum Curricular; Documentos.

\begin{abstract}
The successive changes in Brazilian educational policies have caused aggravating consequences in education. Therefore, this article aims to highlight how the process of elaboration of the Common National Curriculum Base took place through educational documents published since the 1988 Constitution. It is a bibliographic and documentary research, of advanced nature, of exploratory and explanatory nature, and with a qualitative approach, where several documents were studied from the Constitution of 1988 to the last version of the BNCC, and scientific articles. For a better understanding of the research, a chronological order was constructed among the main educational documents. In view of all the work, it is concluded that the implementation process of the BNCC is something that has been planned during the years by only one part of society, which wants our population to follow all capitalist thinking, initially making changes in educational policies, since when we make changes in educational methods we are making changes in the way of thinking of society.
\end{abstract}

Keywords: Education; History; Common National Curriculum Base; Documents.

\section{Resumen}

Los sucesivos cambios en las políticas educativas brasileñas han causado consecuencias agravantes en la educación. Por lo tanto, este artículo tiene como objetivo destacar cómo el proceso de elaboración de la Base Curricular Nacional Común se llevó a cabo a través de documentos educativos publicados desde la Constitución de 1988. Se trata de una investigación bibliográfica y documental, de carácter avanzado, de carácter exploratorio y explicativo, y con un enfoque cualitativo, donde se estudiaron varios documentos desde la Constitución de 1988 hasta la última versión del BNCC, y artículos científicos. Para una mejor comprensión de la investigación, se construyó un orden cronológico 
entre los principales documentos educativos. En vista de todo el trabajo, se concluye que el proceso de implementación del BNCC es algo que ha sido planeado a lo largo de los años por una sola parte de la sociedad, que quiere que nuestra población siga todo el pensamiento capitalista, inicialmente haciendo cambios en las políticas educativas, ya que cuando hacemos cambios en los métodos educativos estamos haciendo cambios en la forma de pensar de la sociedad.

Palabras clave: Educación; Historia; Base Común del Currículo Nacional; Documentos.

\section{Introdução}

Ancorada na Lei de Diretrizes e Bases da Educação Nacional (LDB) e no Plano Nacional de Educação (PNE), e orientada pelos princípios éticos, políticos e estéticos definidos pelas Diretrizes Curriculares Nacionais (DCNs), a Base Nacional Comum Curricular (BNCC) é um documento normativo que trata das aprendizagens essenciais da educação brasileira, aparentemente de modo orgânico e progressista (Brasil, 2018).

A elaboração de uma base nacional comum curricular não foi algo que se deu de um dia para o outro, mas tem sido implantada de forma lenta há mais ou menos trinta anos. Lima (2016), relator da Comissão de Especialistas, confirma tal pensamento quando diz que, “a ideia da Base, mesmo que não tenha esse nome, vem lá da Constituição, passa pelo que está na LDB e se torna mais explícita nas diretrizes".

Freitas, Silva e Leite (2018, p. 866) dizem que a BNCC possui algumas diretrizes invisíveis e dentre elas pode citar-se os "recursos de forte classificação e fraco enquadramento", que significa que ela tem o objetivo de selecionar e estruturar no currículo aquilo que considera como importante e que se "propõe a assumir uma dimensão de verdade. "

Marsiglia et al (2017, p. 119) acrescenta dizendo que ao dar ênfase as "competências", as "habilidades", os "procedimentos" e a "formação de atitudes" e não salientar os conteúdos escolares, o trabalho educativo e o ensinar, o documento traz uma perspectiva que visa adequar os estudantes ao mercado de trabalho ou mais precisamente, ao "empreendedorismo". Isto é, com o aumento do desemprego e a consecutiva redução do trabalho formal, o proposito dessa formação "é preparar os filhos da classe trabalhadora para o mundo do trabalho informal e precarizado, compatível com as novas demandas do capital para este século, voltadas para a acumulação 'flexível’”.

Observa-se que enquanto é proposto a universalização da educação como principal objetivo, encontra-se nos documentos, controvérsias para o alcance de tal finalidade. Embora exista um discurso dito "progressista", é perceptível que há uma rejeição da universalidade da educação, ao limitar a relevância de aprendizagem (RABELO; JIMENEZ; SEGUNDO, 2015, p. 16).

Deste modo, o presente artigo tem o objetivo de realizar um estudo bibliográfico e documental sobre a história da educação no Brasil, analisando os documentos educacionais desde a publicação da Constituição da República Federativa do Brasil (1988) até a última versão da BNCC (2018).

A metodologia utilizada para a elaboração da pesquisa é de natureza avançada, de caráter exploratório e explicativo, e com uma abordagem qualitativa, onde foi realizado um estudo bibliográfico e documental, utilizando como os principais instrumentos para o desenvolvimento do trabalho documentos educacionais e artigos científicos.

Pereira et al (2018, p. 67) explica que o método qualitativo é aquele em que a interpretação do pesquisador é relevante, podendo atribuir ao seu trabalho considerações sobre o objeto de pesquisa.

Para se conseguir obter os resultados esperados foi criado uma linha cronológica entre os documentos, levando em consideração o ano em que foi publicado e sancionado e sua relevância para a educação brasileira nos últimos anos. Os artigos estudados em questão, auxiliaram para realizar uma crítica acerca da BNCC e sua implementação.

Ao final da pesquisa concluiu-se que a Base Nacional Comum Curricular é algo que tem sido construída na história da educação brasileira durante os últimos trinta anos, e principalmente, sendo implantada de forma imperceptível no pensamento das pessoas para considerá-la como algo benéfico, e não questionar o seu principal objetivo. 


\section{Da Constituição de 1988 à Base Nacional Comum Curricular}

Em se tratando de educação, a Constituição de 1988 é a mais elaborada em comparação às anteriores. Nela são encontrados dez artigos sobre educação (arts. 205 a 214). Especificamente no artigo 210 da Constituição de 1988, já se prevê uma Base Nacional Comum Curricular: "Serão fixados conteúdos mínimos para o ensino fundamental, de maneira a assegurar formação básica comum e respeito aos valores culturais e artísticos, nacionais e regionais.” (BRASIL, 1988)

Passados alguns anos desde a promulgação da Constituição de 1988, em 20 de dezembro de 1996 é aprovada a LDB, Lei n 9.394/96, considerada a legislação central da educação brasileira. Nessa época já se falava de uma Base Nacional Comum Curricular. O artigo 26 da LDB de 1996 diz que:

Art. 26. Os currículos da educação infantil, do ensino fundamental e do ensino médio devem ter base nacional comum, a ser complementada, em cada sistema de ensino e em cada estabelecimento escolar, por uma parte diversificada, exigida pelas características regionais e locais da sociedade, da cultura, da economia e dos educandos.

No ano seguinte, após a LDB de 1996 ter sido aprovada, o Ministério da Educação (MEC) elaborou, primeiramente para o Ensino Fundamental I, Parâmetros Curriculares Nacionais (PCNs). Quando se fala de BNCC, entende-se os PCNs como uma espécie de base, pois tal programa dá direções de como os professores devem trabalhar com os seus alunos. Corroborando com essa ideia, os PCNs (1997, p. 14) dizem que a LDB fortalece a necessidade de assegurar uma formação básica comum a todos.

Continuando o assunto acerca dos PCNs, em 1998 são elaborados os PCNs para o Ensino Fundamental II. Quando se trata de BNCC, os PCNs do Ensino Fundamental II (1998, 49 - 50) argumentam que, se há diferenças sociais e culturais que mostram que existem necessidades de aprendizagens diferenciadas, há também algo que é comum a todos, que todo aluno brasileiro independente de sua localidade tem o direito a aprender. Acrescenta também que adotar os "[...] parâmetros curriculares comuns para todo o país, ao mesmo tempo em que contribui para a construção da unidade, busca garantir o respeito à diversidade."

No ano 2000 foram lançados os Parâmetros Curriculares Nacional para o Ensino Médio (PCNEM). Defendendo a ideia da construção de uma BNCC, os PCNEM (2000) expõem que a base nacional comum organizada em áreas de conhecimentos não acarretará no empobrecimento de conteúdos. Tal pensamento se contradiz quando o mesmo explica que passará a selecionar os conteúdos que são importantes “[...]para o desenvolvimento pessoal e para o incremento da participação social" (2000, p. 18).

No mesmo período em que se elaboravam os PCNs e os PCNEM, também eram elaboradas as DCNs para as três etapas da Educação Básica (que viria a passar por diversas mudanças durante os anos seguintes). "As Diretrizes Curriculares Nacionais Gerais para a Educação Básica visam estabelecer bases comuns nacionais para a Educação Infantil, o Ensino Fundamental e o Ensino Médio" (Brasil, 2013, p. 8).

Em 2010, no período de 28 de março a 01 de abril aconteceu a Conferência Nacional de Educação (Conae). Visando PNE, lançado em 2011 e que traçou o rumo da educação até 2020, a Conae (2010, p. 38) destacou a seguinte diretriz a ser considerada: "indicação das bases epistemológicas que garantam a configuração de um currículo que contemple, ao mesmo tempo, uma base nacional demandada pelo sistema nacional de educação e as especificidades regionais e locais", evidenciando assim que um dos principais focos do encontro foi discutir a elaboração da base nacional comum curricular.

Passados alguns meses após a Conae, no dia 13 de julho de 2010, o MEC divulgou um projeto de resolução que definiu as novas DCNs. A partir dessa resolução, em 2013 foram lançadas. A Resolução nº 4 (2010) propôs que a base nacional comum, os conteúdos próprios de cada disciplina e a parte diversificada (conteúdos transdisciplinares/transversais) 
não poderiam ser trabalhados isoladamente, com o argumento de que uma apoia-se e enriquece a outra. Ainda na seção que trata sobre o Ensino Médio, a resolução propôs a ideia de "currículos flexíveis", e tal ideia foi consolidada na BNCC.

Em 2014 foi sancionada a Lei n. 13.005, de 25 de junho de 2014, que aprovou o novo PNE. Dividido em quatro blocos, o PNE possui vinte metas e diversas estratégias, dessas vinte metas, quatro falam sobre a BNCC. São elas: metas 2, 3 , 7 e 10 - estratégias 2.1; 3.2; 7.1 e 10.6, respectivamente (Brasil, 2014).

Ainda em 2014, entre os dias 19 e 23 de novembro aconteceu em Brasília II Conae. Sobre a elaboração de uma base comum curricular, a II Conae (2014) traça diversas estratégias e, dentre elas, pode ser destacada a seguinte:

Aperfeiçoar as diretrizes curriculares nacionais, de maneira a assegurar a formação básica comum e o respeito aos valores culturais e artísticos nos diferentes níveis, etapas e modalidades da educação, atendendo as especificidades de cada região (Brasil, 2014, p. 27).

Passado um ano da promulgação do PNE, entre os dias 17 a 19 de junho, ocorreu o I Seminário Interinstitucional para elaboração da BNCC. Tal evento é considerado um marco na história da Educação Brasileira, pois a partir desse encontro, através da Portaria n. 592, de 17 de junho de 2015, instituiu-se a Comissão de Especialistas para a Elaboração de Proposta da BNCC.

No dia 16 de setembro de 2015 foi lançada a primeira versão da BNCC. No fim do mesmo ano, entre os dias 2 a 15 de dezembro, aconteceu em diversas escolas de todo o País uma mobilização para se discutir sobre a primeira versão da base.

Logo depois desse ato, no dia 3 de maio de 2016 foi divulgada a $2^{\text {a }}$ versão da BNCC. Posteriormente, no período de 23 de junho a 10 de agosto de 2016, o Conselho Nacional de Secretários de Educação (Consed) e a União Nacional dos Dirigentes Municipais (Undime) promoveram em cada estado seminários com os seus profissionais da educação para debaterem sobre a segunda versão da BNCC. Após terem sido realizados os seminários, ainda em agosto de 2016 começou a ser elaborada a terceira versão da BNCC.

Em abril de 2017, o MEC entregou ao CNE a terceira versão da BNCC. A partir daí o CNE elaborou um projeto de resolução que foi enviado ao MEC. E finalmente, no dia 20 de dezembro de 2017, através da Portaria n. 1.570, de 20 de dezembro de 2017, o então Ministro da Educação Mendonça Filho homologa a BNCC.

Apenas dois dias após ter sido homologada, no dia 22 de dezembro de 2017, o CNE divulga a Resolução CNE/CP nº 2, de 22 de dezembro de 2017 que "Institui e orienta a implantação da Base Nacional Comum Curricular, a ser respeitada obrigatoriamente ao longo das etapas e respectivas modalidades no âmbito da Educação Básica."

No dia 2 de abril de 2018 o MEC entrega a versão final da BNCC do Ensino Médio ao CNE. Partindo daí, foi iniciado um processo de audiências públicas para que fosse discutida a versão do Ensino Médio. E por fim, ao final do ano de 2018, no dia 14 de dezembro, o Ministro da Educação Rossieli Soares homologou a versão final para a BNCC do Ensino Médio.

\section{Base Nacional Comum Curricular}

\section{Primeira Versão (2015)}

Na versão preliminar, a BNCC é formada pelos conhecimentos fundamentais que todo estudante deve ter acesso para que seus Direitos à Aprendizagem e ao Desenvolvimento possam ser garantidos (BRASIL, 2015, p. 15).

Silva e Almeida (2018) descrevem que os conhecimentos fundamentais para a Educação Básica são:

Pluralidade das práticas culturais, Valorização dos saberes, compreender e utilizar Linguagens, Preservação de patrimônios, formação e atuação política, Integração entre trabalho, ciência, tecnologia e cultura, Apropriação de conceitos e procedimentos, Historicidade, Reflexão crítica, Cuidado de si, Autonomia frente a situações problema, Atuação consciente, Integração de interesses e motivações e compreensão da centralidade do trabalho. 


\section{Segunda Versão (2016)}

Não tão diferente da primeira versão, a segunda versão da BNCC está fundamentada em princípios éticos, políticos e estéticos para definir os Direitos de Aprendizagem e Desenvolvimento, que devem ser o objeto de toda a educação básica (BRASIL, 2016).

De acordo com Silva e Almeida (2018), “a segunda versão mantém boa parte da estrutura da Base lançada um ano antes.” O que se observa é que a segunda versão é bem mais desenvolvida do que a versão de apresentação.

\section{A Reforma do Ensino Médio (2017) e a Terceira Versão da BNCC (2018)}

A terceira versão da BNCC foi divulgada após ter ocorrido a Reforma do Ensino Médio sancionada pela Lei ${ }^{\circ}$ 13.415, de 16 de fevereiro de 2017.

A Lei ${ }^{\circ} 13.415$, de 16 de fevereiro de 2017:

Altera as Leis $\mathrm{n}^{\circ} \mathrm{s}$ 9.394, de 20 de dezembro de 1996, que estabelece as diretrizes e bases da educação nacional, e 11.494, de 20 de junho 2007, que regulamenta o Fundo de Manutenção e Desenvolvimento da Educação Básica e de Valorização dos Profissionais da Educação, a Consolidação das Leis do Trabalho - CLT, aprovada pelo Decreto-Lei $\mathrm{n}^{\circ} 5.452$, de $1^{\circ}$ de maio de 1943, e o Decreto-Lei n ${ }^{\circ} 236$, de 28 de fevereiro de 1967; revoga a Lei ${ }^{\circ} 11.161$, de 5 de agosto de 2005; e institui a Política de Fomento à Implementação de Escolas de Ensino Médio em Tempo Integral.

A principal mudança da Medida Provisória no 746 para o currículo corresponde ao artigo 36 da LDB n 9.394/1996, que passa a ter o seguinte texto:

Art. 36. O currículo do ensino médio será composto pela Base Nacional Comum Curricular e por itinerários formativos, que deverão ser organizados por meio da oferta de diferentes arranjos curriculares, conforme a relevância para o contexto local e a possibilidade dos sistemas de ensino, a saber:

I - linguagens e suas tecnologias;

II - matemática e suas tecnologias;

III - ciências da natureza e suas tecnologias;

IV - ciências humanas e sociais aplicadas;

V - formação técnica e profissional (BRASIL, 2017).

Motta e Frigotto (2017, p. 361) descrevem que os responsáveis por promoverem a reforma, consideram que o currículo possui muitas disciplinas "inúteis" ou "desinteressantes" e que devido a isso existe um alto percentual de evasão no Ensino Médio, e que para diminuir isso faz-se necessário realizar alterações no currículo.

Corroborando com tal argumentação Santos e Nagashima (2017, p. 180) diz que "A proposta da reforma do Ensino Médio é flexibilizar o currículo. Para isso, será preciso abrir espaço na grade curricular e rever as 13 disciplinas que atualmente a compõem".

\section{Considerações Finais}

O desenvolvimento do presente trabalho proporcionou realizar um estudo sobre a História da Educação no Brasil e comprovar que durante os últimos anos a educação no nosso país tem sofrido drásticas mudanças afetando diretamente todos os que estão envolvidos nela, sejam esses estudantes ou professores.

Podemos argumentar que o processo de implementação da BNCC não foi algo que aconteceu da noite para o dia, mas foi algo planejado por apenas um setor da sociedade, que tem desejado uma total sociedade capitalista com o estado mínimo.

Ainda que o processo de implementação da BNCC tenha acontecido de forma contínua, o que se observa é que a cada versão termos educacionais são trocados ou suprimidos; por exemplo, "direitos de aprendizagem" são substituídos por 
"competências e habilidades". Com isso fica fácil perceber o retrocesso, seja entre a primeira ou última versão, ou entre a segunda e a última versão.

Além disso, percebe-se que os argumentos discursivos encontrados nas três versões são cheios de contradições e distorções e que, apesar de possuírem caráter normativo, falham quando desejam direcionar o público-alvo, seja ele professor ou aluno, o que evidencia que, para ser um documento que irá exercer em favor de uma educação democratizante, ele falha.

A ideia de itinerário formativo e flexibilização do currículo só irá favorecer a classe mais alta da sociedade e as escolas particulares, onde os estudantes das mesmas conseguirão estudar todas as disciplinas, pois apenas as escolas particulares serão capazes de oferecer todos os itinerários formativos.

Dada a importância do assunto, torna-se necessária a realização de estudos que abordem o tema sobre como tem sido estruturado nos últimos anos da educação brasileira através de tantas mudanças que tem ocorrido nas leis educacionais, como também estudos que possam comprovar que houve mudanças não apenas na estrutura de ensino, mas também nas disciplinas estudadas durantes todos os anos da educação básica.

\section{Referências}

Brasil. (1988). Constituição da República Federativa do Brasil. http://www.planalto.gov.br/ccivil_03/constituicao/constituicaocompilado.htm

Brasil. (1996). Lei no 9.394, de 20 de dezembro de 1996. Estabelece as diretrizes e bases da educação nacional. http://www.planalto.gov.br/ccivi 1_03/leis /19394.htm

Brasil. (1997). Parâmetros curriculares nacionais: introdução aos parâmetros curriculares nacionais. Brasília, DF. http://portal.mec.gov.br/seb/arqui vos/pdf/ livro01.pdf

Brasil. (1998). Parâmetros curriculares nacionais: terceiro e quarto ciclos do ensino fundamental: introdução aos parâmetros curriculares nacionais. Brasília, DF. http://portal.mec.gov.br/seb/arquivos/pdf/introducao.pdf

Brasil. (2000). Parâmetros Curriculares Nacionais: Ensino Médio. Brasília, DF. http://portal.mec.gov.br/seb/arquivos/pdf/blegais.pdf

Brasil. (2010). Resolução $\mathrm{n}^{\mathbf{0}}$ 4, de 13 de julho de 2010. Define Diretrizes Curriculares Nacionais Gerais para a Educação Básica. http://portal.mec.gov.br/dmdocuments/rceb004_10.pdf

Brasil. (2013). Diretrizes Curriculares Nacionais Gerais da Educação Básica. Brasília: MEC, SEB, DICEI. <http://portal.mec.gov.br/index.php?option=com_docman\&view=download\&alias=15548-d-c-n-educacao-basica-nova-pdf\&Itemid=30192

Brasil. (2014). Lei no 13.005, de 25 de junho de 2014. Aprova o Plano Nacional de Educação - PNE e dá outras providências. http://www.planalto.gov.br/C CIVIL_03/_A to2011-2014/2014/Lei/L13005.htm

Brasil. (2014). Planejando a Próxima Década: Conhecendo as 20 Metas do Plano Nacional de Educação. Brasília, DF. http://pne.mec.gov.br/images/pdf pne_conhecendo_20_metas.pdf

Brasil. (2015). Base Nacional Comum Curricular. Brasília, DF. http://basenacionalcomum.mec.gov.br/images/relatorios-analiticos/BNCC-APRESEN TACAO.pdf

Brasil. (2015). Base Nacional Comum Curricular. Encaminhamento para revisão do documento preliminar da BNCC: proposições a partir dos dados da consulta pública. Brasília, DF. http://basenacionalcomum.mec.gov.br/images/relatorios-analiticos/REVISAO_DOCUMENTO_PRELIMINARPROPOSICOES_\%20INICIAIS.pdf

Brasil. (2015). Portaria n ${ }^{\circ}$ 592, de 17 de junho de 2015. Institui Comissão de Especialistas para a Elaboração de Proposta da Base Nacional Comum Curricular. https://www.jusbrasil.com.br/diarios/94124972/dou-secao-1-18-06-2015-pg-16

Brasil. (2016). Base Nacional Comum Curricular. Anexo I - síntese da contribuição dos Estados. Brasília, DF. http://basenacionalcomum.me c.gov.br/imag es/relatorios-analiticos/Relatorios-Sintese\%20dos\%20Estados.pdf

Brasil. (2016). Base Nacional Comum Curricular. Seminários Estaduais da BNCC: Posicionamento conjunto de Consed e Undime sobre a segunda versão da Base Nacional Comum Curricular. Brasília, DF. http://basenacionalcomum.mec.gov.br/images/relatorios-analiticos/Posicionamen to\%20Conse d\%20e\%20 Undime.pdf

Brasil. (2016). Base Nacional Comum Curricular: 2a versão revista. Brasília, DF. http://basenacionalcomum.mec.gov.br/images/relatorios-analiticos/bncc2versao.revista.pdf

Brasil. (2016). Medida Provisória 746, de 22 de setembro de 2016. Institui a Política de Fomento à Implementação de Escolas de Ensino Médio em Tempo Integral, altera a Lei n ${ }^{\circ} 9.394$, de 20 de dezembro de 1996, que estabelece as diretrizes e bases da educação nacional, e a Lei ${ }^{\circ} 11.494$ de 20 de junho 2007 , que regulamenta o Fundo de Manutenção e Desenvolvimento da Educação Básica e de Valorização dos Profissionais da Educação, e dá outras providências. http://www.planalto.gov.br/ccivil_03/_ato2015-2018/2016/Mpv/mpv746.htm 
Brasil. (2017). Lei 13.415, de 16 de fevereiro de 2017. Altera as Leis $\mathrm{n}^{\circ}$ 9.394, de 20 de dezembro de 1996, que estabelece as diretrizes e bases da educação nacional, e 11.494, de 20 de junho 2007, que regulamenta o Fundo de Manutenção e Desenvolvimento da Educação Básica e de Valorização dos Profissionais da Educação, a Consolidação das Leis do Trabalho - CLT, aprovada pelo Decreto-Lei ${ }^{\circ}{ }^{5.452}$, de $1^{\circ}$ de maio de 1943 , e o Decreto-Lei $n^{\circ} 236$, de 28 de fevereiro de 1967; revoga a Lei no 11.161, de 5 de agosto de 2005; e institui a Política de Fomento à Implementação de Escolas de Ensino Médio em Tempo Integral. http://www.planalto.gov.br/ccivil_03/_Ato2015-2018/2017/Lei/L13415.htm

Brasil. (2017). Portaria $\mathrm{n}^{\circ}$ 1.570, de 20 de dezembro de 2017. Homologa o Parecer CNE/CP n- 15/2017, do Conselho Pleno do Conselho Nacional de Educação, aprovado na Sessão Pública de 15 de dezembro de 2017. http://basenacionalcomum.mec.gov.br/images/hi storico/PORTARIA1570DE2 2DEDEZEMBRODE2017.

Brasil. (2017). Resolução $\mathrm{n}^{\circ}$ 2, de 22 de dezembro de 2017. Institui e orienta a implantação da Base Nacional Comum Curricular, a ser respeitada obrigatoriamente ao longo das etapas e respectivas modalidades no âmbito da Educação Básica. <http://basenacionalcomum.mec.gov.br/imag es/historico/RESOLUCAOCNE_CP222DEDEZEMBRODE2017.pdf

Brasil. (2018). Base Nacional Comum Curricular: educação é a base. Brasília, DF. http://basenacionalcomum.mec.gov.br/image s/BNCC_ EI_EF_110518_versaofinal_site.pdf

Brasil. Conferência Nacional De Educação. (2010). Construindo o Sistema Nacional Articulado: O Plano Nacional de Educação, Diretrizes e Estratégias de Ação. Brasília, DF. http://Conae.mec.gov.br/images/stories/pdf/pdf/documetos/documento_final_sl.pdf

Brasil. Conferência Nacional De Educação. (2014). O PNE na Articulação do Sistema Nacional de Educação: Participação Popular, Cooperação Federativa e Regime de Colaboração. Brasília, DF. http://fne.mec.gov.br/images/doc/DocumentoFina240415.pdf

Brasil. Ministério da Educação. (2016). Discussão sobre o currículo é anterior à proposta da Base. http://portal.mec.gov.br/ultimas-noticias/211218175739/34521-discussao-sobre-curriculo-e-anterior-a-proposta-da-base

Freitas, M. T.; Silva, J. A. da. \& Leite, M. C. L. (2018). Diretrizes invisíveis e regras distributivas nas políticas curriculares da nova BNCC. Currículo sem Fronteiras, 18(3), 857-870. http://www.curriculosemfronteiras.org/vol18iss3articles/freitas-silva-leite.pdf

Marsiglia, A., Pina, L., Machado, V., \& Lima, M. (2017). A Base Nacional Comum Curricular: um novo episódio de esvaziamento da escola no Brasil. Germinal: Marxismo E Educação Em Debate, 9(1), 107-121. http://dx.doi.org/10.9771/gmed.v9i1.21835

Motta, Vânia Cardoso da, \& Frigotto, Gaudêncio. (2017). Por que a urgência da Reforma do Ensino Médio? Medida Provisória $n^{\circ} 746 / 2016$ (Lei ${ }^{\circ}$ 13.415/2017). Educação \& Sociedade, 38(139), 355-372. https://doi.org/10.1590/es0101-73302017176606

Pereira, A. S. et al. (2018). Metodologia da pesquisa científica. UFSM. https://repositorio.ufsm.br/bitstream/handle/1/15824/Lic_Computacao_MetodologiaPesquisa-Cientifica.pdf

Rabelo, J. Jimenez, S. \& Segundo, M. D. M. (2015). O movimento de educação para todos e a crítica marxista. (1) Fortaleza: Imprensa Universitária da Universidade Federal do Ceará (UFC). http://repositorio.ufc.br/bitstream/riufc/16670/1/2015_liv_jrabelo.pdf

Santos, D. M. \& Nagashima, L. K. (2017). A Base Nacional Comum Curricular: a reforma do ensino médio e a organização da disciplina de química. Revista Pedagogia em Foco, 12(7), 175-191. http://revista.facfama.edu.br/index.php/PedF/article/view/264/215

Silva, M. A. D. da. \& Almeida, P. F. de. (2018). Um estudo comparativo das versões da Base Nacional Comum Curricular para o ensino médio. Anais eletrônicos. Congresso Nacional de Educação, Recife, PE, Brasil, 5. http://www.editorarealize.com.br/revistas/conedu/trabal hos/TRABALHO_EV11 7_MD1_SA2_ID1182_11092018224306.pdf 